\title{
15. Development
}

\author{
Bob Warner
}

\section{The Australian National University, Australia}

The inclusion of targets for access to improved water and sanitation in the Millenium Development Goals (MDGs) reflected a clear appreciation in developing countries and their partners of the critical role that water and sanitation services play in people's wellbeing. The costs incurred when people cannot acquire safe drinking water, or do not use hygenic sanitation practices are large: a recent World Health Organization (WHO) study estimated the global economic losses associated with inadequate water supply and sanitation to be US $\$ 260$ billion a year, or 1.5 per cent of the GDP of the countries included in the study (WHO 2012).

Typically, although not exclusively, it is the poor who have limited access and bear the bulk of these costs. Further, the majority of those without access live in rural areas - 89 per cent of those without access to improved water, and 70 per cent of those without improved sanitation (Sy et al. 2014). These factors mean that capacity to manage costs, and to take action to reduce the risk of incurring them, is limited.

The distillation of the water and sanitation challenge into two measurable targets has helped focus attention and attract commitment of financial resources to dealing with the issue. But it also risks masking the complexity of the problems associated with reducing the costs of using unsafe water and unhygenic sanitation.

For water, some of the complexities arise because of the nature of water as an economic good and the need for societies to find ways of managing tradeoffs between alternative uses, as well as to address strong social expectations concerning access to a necessity of life. A further level of complexity arises because of the need for robust institutions: to devise and implement policy, to manage water resources, and to provide water-supply services to households.

These complexities can be challenging in developed countries, but they are exacerbated in developing countries by the constrained functionality of formal institutions that would underpin market solutions, and limited capacity of public sectors to provide water or to regulate provision. Property rights in general, not just with respect to water, are hard to define and protect, and the means to resolve disputes that cross communal boundaries are often absent or dysfunctional. This can constrain adoption of private and communal solutions that require scale to be viable (for example, where water needs treatment and 
transmission and distribution structures). And in most developing countries, governments do not have the financial and managerial capacity (and in some cases the interest) to provide public sector solutions, or to implement policies to manage externalities associated with use of water resources.

Typically, the majority of households in developing countries rely on private (including self-provision) and community initiative to meet their water needs. (A recent study of private water provision in Bangladesh, Benin and Cambodia, for example, estimated that only 11 per cent of the total population of these countries get their water from state-run systems, Sy et al 2014.) In the foreseeable future, this pattern is unlikely to change, especially for poor and rural households. Policy makers - and their development partners - are thus increasingly focusing on what is required to help ensure that private and communal provision delivers safe water, and that households are able to pay for it. Among other things, this requires understanding the market for water and the drivers of household demand, calibrating the enabling environment for private sector investment in water supply, and developing policies that address the ability to pay of poor households that often have seasonal or volatile cash incomes.

\section{Overview of chapters}

In the development section of this volume there are six contributions that illustrate a selection of the complexities involved in addressing the water needs of poor people in developing countries, and ways in which new solutions may be emerging. Bain et al. (Chapter 16) show how the indicator used in the MDGs - which measures access to a water source that is likely to be protected from outside contamination - may give a misleading impression of the extent to which people are using water that is safe to drink. They argue that if the data are adjusted for water quality, a much higher proportion of the world's population still lacks access to safe water than progress towards the MDG target implies. In a similar vein, Vedachalam (Chapter 17) provides evidence from urban centres in India that access to improved water sources does not necessarily translate into regular availability of safe water: constrained supply from improved sources drives households to augment piped supplies with other, less reliable water. He also argues that the sustainability of some improved water sources is under threat from depletion and contamination. Karim et al. (Chapter 20) examine the complex social effects that can arise if development projects and technology alter the balance between competing uses of water sources. Their paper explores the impact on within-household gender violence of the installation of deep tube wells for irrigation that reduce the ability of hand pumps to provide water for domestic purposes. Berg (Chapter 19) considers the challenges of regulating 
state-owned water utilities, and the fact that regulation alone cannot sustain service delivery unless supporting insitutions and structures are in place. He proposes elements of governance and utility organisation that are preconditions for good performance, without which external regulation is unlikely to achieve traction. And finally, Foster et al. (Chapter 18) look at the impact of the revolution in mobile communications in helping to solve one of the great challenges of water supply: facilitating payment and redressing the problem of cost recovery for both public and private water-service providers. Their analysis shows the importance of the opportunity cost of time to customers, and the costs to utilities of operating physical payment offices, and how the introduction of mobile bill payment services offer savings to both sides of the water service market.

Bob Warner is Director, Pacific Research Partnerships at the Crawford School of Public Policy. He was co-author of a recent World Bank Directions in Development publication, on provision of water and sanitation services to the poor by the domestic private sector. His email address is bob.warner@anu.edu.au.

\section{References}

Sy, J. and Warner, R. with Jamieson, J., 2014. Tapping the Markets: opportunities for domestic investments in water and sanitation for the poor. Directions in development, World Bank, Washington D.C.

WHO (World Health Organization), 2012. Global Costs and Benefits of DrinkingWater Supply and Sanitation Interventions to reah the MDG Target and Universal Coverage, WHO/HSE/WSH/12.01 Geneva, Switzerland. 
This text taken from Global Water: Issues and Insights by R. Quentin Grafton, Paul Wyrwoll, Chris White and David Allendes, published May 2014 by ANU Press, The Australian National University, Canberra, Australia. 